\title{
GREEN FUNCTION'S NEW PROPERTY AND ITS APPLICATION TO THE SOLUTION FOR A HIGHER-ORDER FRACTIONAL BOUNDARY VALUE PROBLEM
}

\section{DEXIANG MA}

Abstract. We investigate the higher-order fractional boundary value problem:

$$
\left\{\begin{array}{l}
-D_{0^{+}}^{v} u(t)=a(t) f(t, u(t)), \quad 0<t<1, \\
u(0)=u^{\prime}(0)=u^{\prime \prime}(0)=\cdots=u^{(n-2)}(0)=0, \quad\left[D_{0^{+}}^{\alpha} u(t)\right]_{t=1}=0,
\end{array}\right.
$$

where $v$ and $\alpha$ are two given constants satisfying $n-1<v \leqslant n$ with $n \geqslant 3,0 \leqslant \alpha \leqslant n-2$. Some results have been obtained in literature in case of $1 \leqslant \alpha \leqslant n-2$ or $\alpha=0$, but no result is about $0<\alpha<1$. In this paper, new properties of the Green function associated with the higherorder fractional boundary value problem in case of $0 \leqslant \alpha \leqslant n-2$ are obtained which are the main contribution of the paper. As an application of these properties, the existence of positive solutions of the problem is then established. Our results improve on recent works in literature and fill in their gaps.

Mathematics subject classification (2010): 34A08, 34B18, 34B27, $26 \mathrm{~A} 33$.

Keywords and phrases: Fractional differential equation, cone, positive solution, Green function.

\section{REFERENCES}

[1] A. M. A. EI-SAYED, On the fractional differential equations, Appl. Math. Comput. 49 (1992) 205 213.

[2] A. A. Kilbas And J. J. TRujillo, Differential equations of fractional order: methods, results and problems I, Appl. Anal. 78 (2001) 153-192.

[3] A. A. Kilbas And J. J. TRujillo, Differential equations of fractional order: methods, results and problems II, Appl. Anal. 81 (2002) 435-493.

[4] A. A. Kilbas, H. M. SRivastava and J. J. Trujillo, Theory and Applications of Fractional Differential Equations North-Holland Mathematics Studies, vol. 204, Elsevier Science, B. V. Amsterdam, 2006.

[5] V. Lakshmikantham and A. S. Vatsala, Basic theory of fractional differential equations, Nonlinear Anal. TMA 69 (8) (2008) 2677-2682.

[6] A. OUAHAB, Some results for fractional boundary value problem of differential inclusions, Nonlinear Anal. TMA 69 (11) (2008) 3877-3896.

[7] M. Benchohra, S. Hamania And S. K. NTOuYAs, Boundary value problems for differential equations with fractional order and nonlocal conditions, Nonlinear Anal. TMA 71 (7-8) (2009) 2564 2575.

[8] Y. K. Chang And J. J. NiETo, Some new existence results for fractional differential inclusions with boundary conditions, Math. Comput. Model. 49 (3-4) (2009) 605-609.

[9] R. P. Agarwal, M. Benchohra And S. Hamani, A survey on existence results for boundary value problems of nonlinear fractional differential equations and inclusions, Acta. Appl. Math. 109 (2010) 973-1033.

[10] J. FENG AND Z. YONG, Existence of solutions for a class of fractional boundary value problems via critical point theory, Comput. Math. Appl. 62 (2011) 1181-1199. 
[11] Z. BAI AND H. LU, Positive solutions for boundary value problem of nonlinear fractional differential equation, J. Math. Anal. Appl. 311 (2005) 495-505.

[12] X. XU, D. JIANG AND C. YUAN, Multiple positive solutions for the boundary value problem of a nonlinear fractional differential equation, Nonlinear Anal. TMA 71(10) (2009) 4676-4688.

[13] R. P. AgARwal, D. O'REgan AND S. STANĚK, Positive solutions for Dirichlet problems of singular nonlinear fractional differential equations, J. Math. Anal. Appl. 371 (2010) 57-68.

[14] Y. ZhaO, S. SUn, Z. HAN AND M. ZHANG, Positive solutions for boundary value problems of nonlinear fractional differential equations, Appl. Math. Comput. 217 (2011) 6950-6958.

[15] N. NYAMORADI, Existence of solutions for multi point boundary value problems for fractional differential equations, Arab. J. Math. Sci. 18 (2012) 165-175.

[16] X. YANG, Z. WEI AND W. DONG, Existence of positive solutions for the boundary value problem of nonlinear fractional differential equations, Commun. Nonlinear Sci. Numer. Simulat. 17 (2012) 85-92.

[17] S. Vong, Positive solutions of singular fractional differential equations with integral boundary conditions, Math. Comput. Model. 57 (2013) 1053-1059.

[18] S. ZHANG, Positive solutions to singular boundary value problem for nonlinear fractional differential equation, Comput. Math. Appl. 59 (2010) 1300-1309.

[19] C. S. Goodrich, Existence of a positive solution to a class of fractional differential equations, Appl. Math. Lett. 23 (2010) 1050-1055.

[20] J. R. GRAEFA, L. KONG AND B. YANG, Positive solutions for a fractional boundary value problem, Appl. Math. Lett. 56 (2016) 49-55.

[21] H. A. H. SALEM, On the fractional order m-point boundary value problem in reflexive Banach spaces and weak topologies, J. Comput. Appl. Math. 224 (2009) 565-572. 